\title{
„Stecknadelkopf mit Tuberkelpilzen“
}

\author{
"Pinhead with Tuberculosis Pathogens"
}

\section{Bibliografie}

Dol http://dx.doi.org/

10.1055/s-0032-1309733

Online-Publikation: 23.5.2012

Pneumologie 2012; 66: 480-482

(c) Georg Thieme Verlag KG

Stuttgart · New York

ISSN 0934-8387

\section{Korrespondenzadresse}

Dr. med. Robert Kropp

Das Deutsche Tuberkulose-Archiv

Liegnitzer Straße 5

36100 Petersberg

dr.robert.kropp@gmx.de
Die Sammlungen für das Deutsche TuberkuloseArchiv brachten nicht nur viele Bücher zusammen, die den Aufbau einer veritablen, umfangreichen Bibliothek erlaubten; vielmehr wurden auch zahlreiche Artikel anderweitiger Art zur Geschichte der Tuberkulose gespendet, darunter kuriose Erzeugnisse, ja Unikate, deren Bedeutung zum Teil völlig unbekannt war und erst herausgefunden werden musste. So erhielt das Archiv vor einigen Jahren ein Objekt in Form eines stark vergrößerten Stecknadelkopfes (auch als Streichholzkopf oder Pilzkopf bezeichnet).

Es handelt sich um einen „Stecknadelkopf mit Tuberkelpilzen in etwa tausendfacher Vergrößerung“. Er besteht kompakt aus Gips, ist entsprechend schwer und wirkt massig. Das Objekt hat eine Höhe von etwa $65 \mathrm{~cm}$. Es ist silberfarben überstrichen ( $\mathbf{A b b} \mathbf{1}$ ), die halbrunde Kuppel hat einen größten Durchmesser von etwa $70 \mathrm{~cm}$. Die rissige Oberfläche ist übersät von zahlreichen rotfarbenen Stäbchen von 2-3mm Länge (๑ Abb. 2).

Dieses Gebilde wurde vor Jahren auf einer Behring-Ausstellung in Marburg gezeigt. Die weitere Herkunft muss leider im Dunklen bleiben. Zwar ist nicht vergessen, wer diesen "Stecknadelkopf“ dankenswerterweise dem Deutschen Tuberkulose-Archiv gespendet hat; doch konnten die gründlichen Recherchen keine endgültige Auskunft über Bedeutung, Herkommen und Schicksal dieses Gegenstandes geben.

Bisher wurde lediglich ein einziges weiteres, etwas kleineres, gleichartiges Modell entdeckt ( $\bullet$ Abb.3); es wird im Deutschen Hygiene-Museum in Dresden (DHMD) bewahrt ${ }^{1}$. Sein Besitz kann im DHMD bis zum Jahre 1921 zurückverfolgt werden. In diesem Jahre und noch einmal

\footnotetext{
${ }^{1}$ Unser herzlicher Dank gebührt Frau Susanne Roeßiger und Frau Dr. Sandra Mühlenberend, Deutsches HygieneMuseum Dresden (DHMD), für die Überlassung der Informationen und Bilder.
}

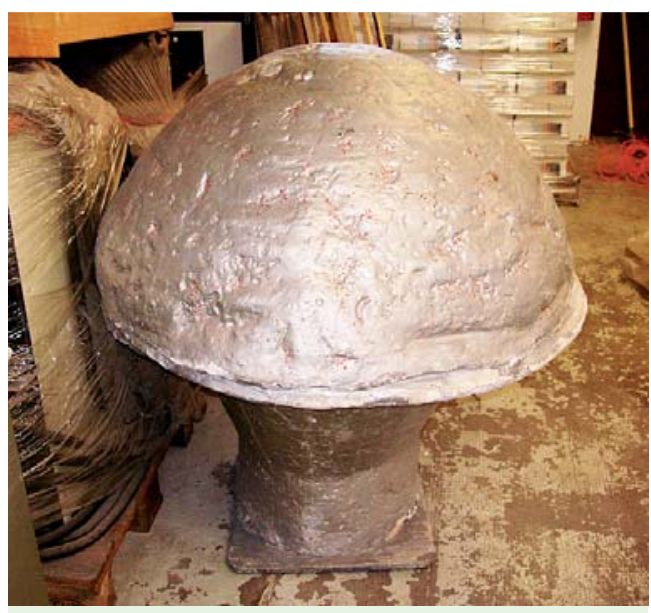

Abb. 1 Der „Stecknadelkopf“ des Deutschen Tuberkulose-Archivs.

$1927^{2}$ wurde es in dortigen Tuberkulose-Ausstellungen gezeigt, „um die Größenverhältnisse der Tuberkuloseerreger anschaulich $\mathrm{zu}$ machen und auf die Ansteckungsgefahr hinzuweisen“. Der Objekttitel hieß: „Stecknadelkopf mit Tuberkelpilzen in 500facher Vergrößerung“. Für die Ausstellung 1921 war der erste Wissenschaftliche Direktor Dr. Friedrich Woithe verantwortlich. Fachliche Beratung kam von Professor Dr. Herbert Beschorner (leitender Arzt des freien Ausschusses zur Bekämpfung der Schwindsucht) und Professor Dr. Paul Geipel (anerkannter Pathologe) aus Dresden. Das Objekt war damals auf einem Sockel montiert $(\bullet$ Abb.4), dessen Originalbeschriftung lautete: „Um eine Vorstellung von der Kleinheit der Tuberkelpilze zu geben, ist der 1,5 mm dicke Kopf einer Stecknadel in 500-facher Vergrößerung nachgebildet worden. Die Oberfläche der Nachbildung

\footnotetext{
2 Nach den uns freundlicherweise überlassenen Unterlagen des DHMD wurde der „Stecknadelkopf“ 1921 und 1927 auf Tuberkulose-Ausstellungen gezeigt.
} 


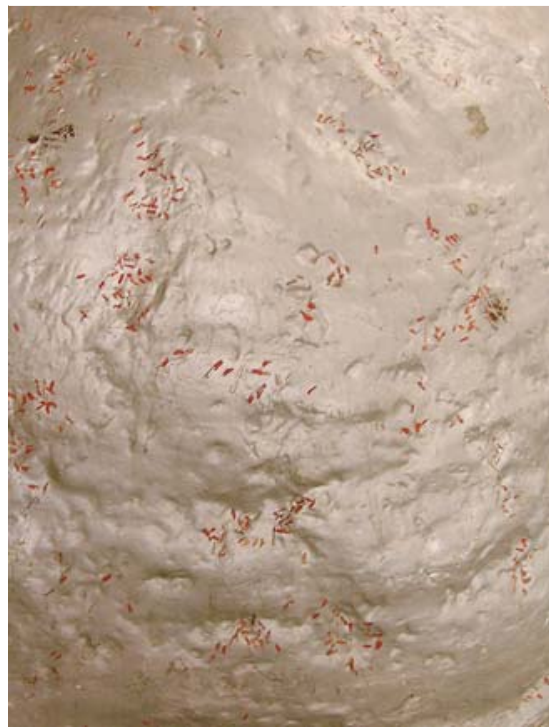

Abb. 2 Oberfläche des "Stecknadelkopfs“ mit rotgefärbten Tuberkulosebakterien (Tuberkelpilzen).

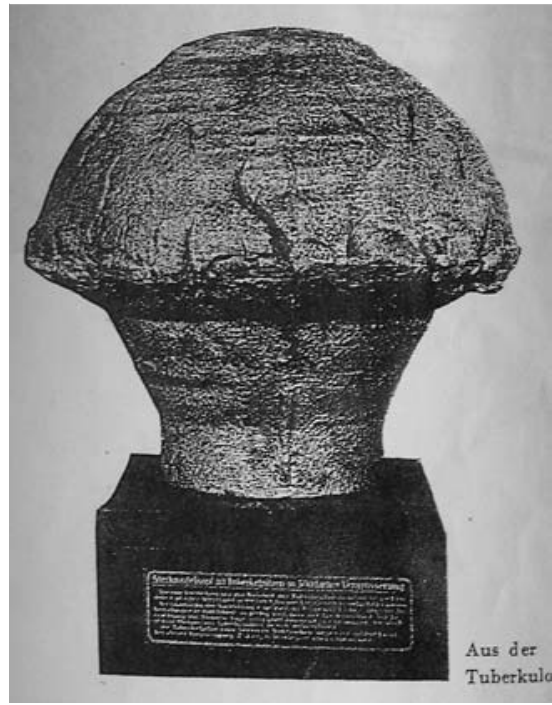

Abb. 3 Der „Stecknadelkopf“ des DHMD.

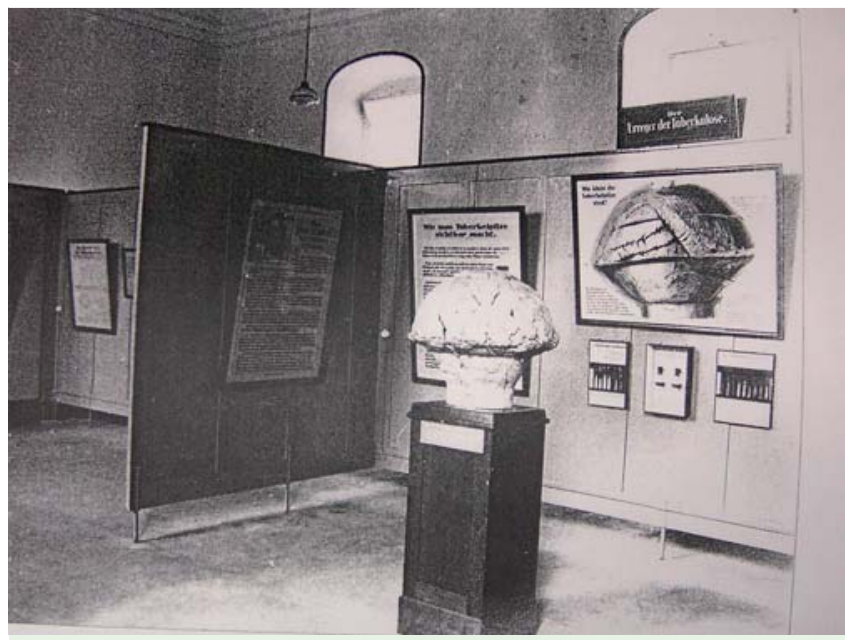

Abb.4 Präsentation des "Stecknadelkopfs“ in der Ausstellung des DHMD 1927.

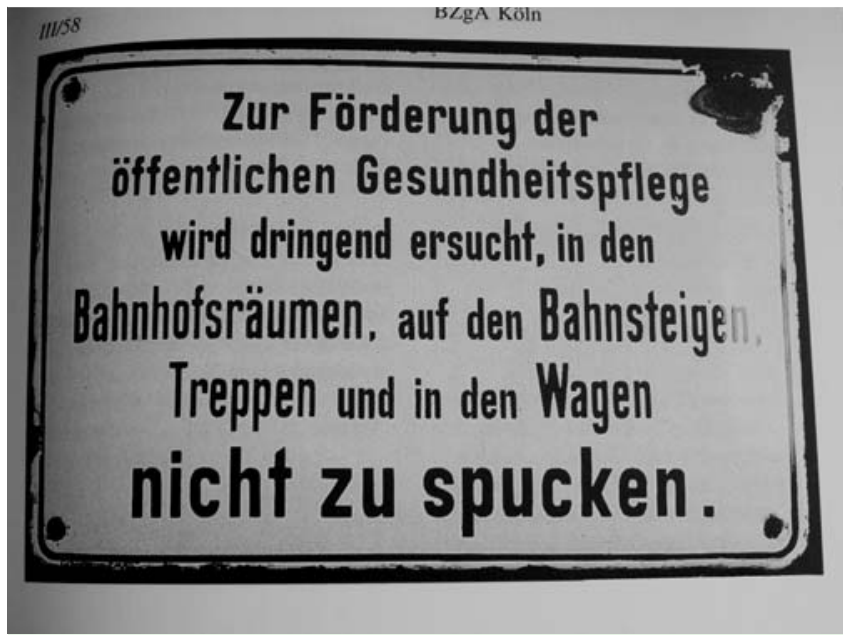

Abb.5 Ein Beispiel für die konsequente Aufklärung über die Tuberkulose.

(bisher) nicht bestätigen. Ob insbesondere Karl August Lindner, der Gründer des DHMD, der Ideengeber war, muss gleichfalls ungewiss bleiben; der „Stecknadelkopf“ passt allerdings gut zu dem von ihm entwickelten Programm des DHMD, der populärwissenschaftlichen Vermittlung von Kenntnissen rund um die Themen Mensch, Gesundheit, Krankheit mit anschaulichen, unterhaltsamen Objekten.

Die Darstellung der Tuberkulosebakterien auf einem Stecknadelkopf hat noch eine weitere, vergleichende Bedeutung, da die Tuberkel, eine der häufig vorkommenden morphologischen Erscheinungen der Tuberkulose, oft stecknadelkopf-, hirsekorngroß sind. Jedenfalls passt die Idee des „Stecknadelkopfes“ zu der Aufbruchstimmung um die Jahrhundertwende 1900, im Anschluss an die Kochsche Entdeckung. Die damaligen ausgedehnten Tuberkulose-Forschungen und bemerkenswerten Erfindungen betrafen nicht nur die Diagnostik und die Individualtherapie, wobei zur letztgenannten nur beschränkte Möglichkeiten vor allem hinsichtlich endgültiger Heilung der Krankheit entwickelt werden konnten. Größere Erfolge wurden durch konsequente Aufklärung über die Krankheit sowie über die Wege der Ansteckung und ihre Vermeidung gewonnen (als Beispiel $\bullet$ Abb.5). Hier-

${ }^{3}$ Mündliche Mitteilung von Herrn Dr. W.-D. Freiherr von Freytag-Loringhofen, Marburg, am 18. 10. 2004. 
durch wurde die Häufigkeit der Infektion und der Erkrankung eindrucksvoll vermindert.

Diese Aufklärung sollte nicht nur den Tuberkulosekranken und evtl. ihren Angehörigen zugutekommen. Vielmehr wurde eine Information der gesamten Bevölkerung hinsichtlich der Tuberkulose allgemein, der Tuberkulosebakterien, des klugen Verhaltens bei der Infektvermeidung u.v.m. angestrebt, vor allem durch eine eminente Quantität der wissenschaftlichen Publikationen und der populärwissenschaftlichen Schriften, ferner durch Vor- träge, auch durch Ausstellungen („Tuberkulose-Museen“ [2]). In diesem Umkreise mag der Gedanke zum „Stecknadelkopf“ entstanden sein und er seine Bestimmung gefunden haben.

\section{Literatur}

1 Koch R. Die Aetiologie der Tuberculose. Berliner klin. Wschr 1882; 19 : 221

2 Kropp R. Tuberkulose-Museum - Tuberkulose-Wandermuseum. Pneumologie 2008; 62: 602-606 